UNIVERSIDADE ESTADUAL DE FEIRA DE SANTANA

Autorizada pelo Decreto Federal n ${ }^{\circ} 77.496$ de 27/04/76

Recredenciamento pelo Decreto n ${ }^{\circ} 17.228$ de 25/11/2016

PRÓ-REITORIA DE PESQUISA E PÓS-GRADUAÇÃO

HHHG COORDENAÇÃO DE INICIAÇÃO CIENTÍFICA

XXIII SEMINÁRIO DE INICIAÇÃO CIENTÍFICA DA UEFS

SEMANA NACIONAL DE CIENTÍFICA E TECNOLÓGICA - 2019

\title{
MAPEAMENTO DAS ÁREAS COM PROPENSÃO À EROSÃO NO MUNICÍPIO DE FEIRA DE SANTANA-BA
}

\section{Brenda de Souza Santino ${ }^{1}$; Joselisa Maria Chaves ${ }^{2}$; Simão Mascarenhas} Fernandes $^{3}$ e Rafael Cruz Cordeiro ${ }^{4}$

1. Bolsista PROBIC/UEFS, Graduanda em Agronomia, Universidade Estadual de Feira de Santana, e-mail: brendda.28.bs@gmail.com

2. Orientador, Departamento de ciências Exatas, Universidade Estadual de Feira de Santana, e-mail: joselisa@uefs..br 3, 4.Graduando em Agronomia, Departamento de Ciências biológicas, Universidade Estadual de Feira de Santana,

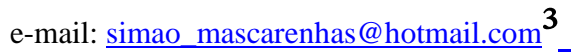 \\ rccordeiro12@gmail.com $^{4}$
}

PALAVRAS-CHAVE: SIG; Caatinga; desmatamento; degradação do solo

\section{INTRODUÇÃO}

A Caatinga é um bioma de ocorrência exclusiva no Brasil, que ocupa aproximadamente $10 \%$ do território nacional, tem sua área principal localizada na região nordeste, onde existe a predominância do clima semiárido (menos de $800 \mathrm{~mm}$ de precipitação/ano), totalizando aproximadamente $734 \mathrm{mil} \mathrm{km}^{2}$ (SILVA et al., 2004; SOUZA et al,.2015).

De acordo com dados do Ministério do Meio Ambiente, esse bioma ocupa mais da metade do estado da Bahia, no entanto encontra-se bastante fragmentado ao longo do território, o que permite uma facilidade da ação antrópica e dificuldade da sua preservação (CASTELLETTI et al., 2004).

Situado no estado da Bahia, o município de Feira de Santana, é a segunda maior cidade do estado, e de acordo com o último censo do IBGE, apresenta uma população de 617.528 habitantes. Esse município, está localizado numa área de transição climática, entre o clima úmido do litoral e o semiárido do interior, aonde ao longo dos anos com a evolução da expansão urbana e desmatamento de áreas para agricultura e pecuária vem perdendo sua diversidade ecológica. (SANTOS et al, 2016). Ainda assim dentro de seu território existem alguns registros de áreas de vegetação nativa, principalmente de Caatinga, que fazem parte das áreas mais susceptíveis a desertificação no país (HAUF, 2010).

Esse trabalho tem como objetivo Identificar as áreas de maior risco de perda de solo devido ao desmatamento da vegetação natural, no município de Feira de Santana, através de ferramentas de modelagem ambiental, associadas ao uso de Sistemas de Informação Geográfica (SIG).

\section{MATERIAL E MÉTODOS}

1. Revisão bibliográfica sobre a temática e construção da Base de Dados;

Nessa etapa, foram pesquisados artigos, teses, publicações técnicas sobre a temática, em plataformas como Google Acadêmico, Scorpus e Scielo, a fim de que pudesse dar suporte à pesquisa. Os dados utilizados nessa pesquisa foram retirados das bases de dados do IBGE, INPE, MAPBIOMAS e Google Earth Engine. Em seguida foram filtrados e processados em ambiente SIG a fim de adequar os arquivos a uma mesma escala e sistema de coordenadas. 
2. Levantamento das áreas de transição de vegetação Nativa para Agropecuária, através da base de dados do MAPBIOMAS de 1985 a 2017;

Nessa etapa, foi adquirido a través da Base de dados do MAPBIOMAS o raster referente à transição de vegetação Nativa para Agropecuária do ano de 1985 a 2017, a fim de poder estimar na série histórica mais longa possível mudanças.

3. Geração de um MDE a partir da imagem SRTM , para extração da declividade

O MDE (Modelo digital de elevação), foi construído por meio do software QuantumGIS, com a utilização do raster SRTM baixado a partir da base de dados do INPE TOPODATA. Foi feito o download de quatro cenas que englobam o município, com resolução espacial de 30 metros referentes ao produto de altimetria disponível no site. Em seguida, no ambiente SIG, foi feito o mosaico das cenas, foi feita a reprojeção do raster para coordenadas planas. Após geração do MDE, foi feita a extração da declividade, em seguida os valores foram agrupados em intervalos segundo os limiares estabelecidos pela EMBRAPA (1979) para declividade e valores de vulnerabilidade a erosão de Crepani et al. (2001).

\section{RESULTADOS E DISCUSSÃO}

De acordo com os dados do levantamento sobre as áreas de transição de Vegetação Natural para Agropecuária adquiridos da Coleção 3 do MapBiomas, durante o período de 1985 a 2017, aproximadamente 13570 ha da vegetação natural da área de estudo foi desmatada para implantação de cultivos alimentícios ou pastagem como pode ser observado no mapa de transição (Figura 1).

Essa alteração se deu principalmente nas regiões Norte, Noroeste, Oeste e Sudoeste do município, onde se concentra uma maior parte de vegetação característica do Bioma Caatinga. Esse padrão é reflexo principalmente da pressão demográfica no semiárido brasileiro, que por vezes exigiu ao longo das últimas décadas um rápido incremento da produção agrícola, o qual tem sido feito às custas do desmatamento indiscriminado da caatinga que tem como uma das principais consequências a degradação do solo, que é maximizada pela utilização de práticas agrícolas não preservacionistas (Albuquerque, et al 2001).

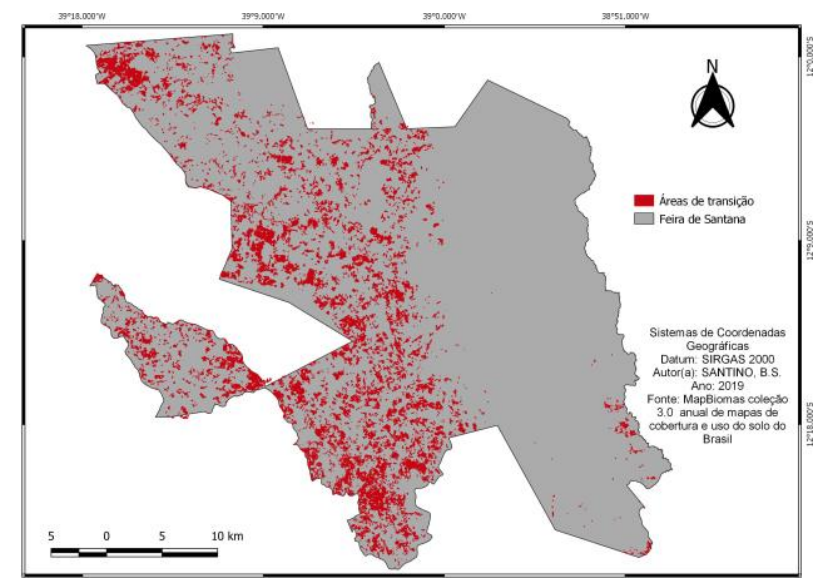

Figura 1. Mapa de transição da classe de Vegetação Nativa para Agropecuária (1985-2017), do Municéipio de Feira de Santana -Ba

Fonte: http://mapbiomas.org/map\#transitions (Acesso: 15 de dezembro de 2018)

Na figura 2 é possível observar o mapa de declividade baseado nas classes de relevo propostos pela EMBRAPA (1979) (Tabela 1). Nele é nota-se que as áreas onde estão os 
maiores declives se concentram na região onde houve maior desmatamento da vegetação nativa no período de 34 anos. Além de dificultar a mecanização, na medida em que se aumenta a declividade, maior a probabilidade de erosão.

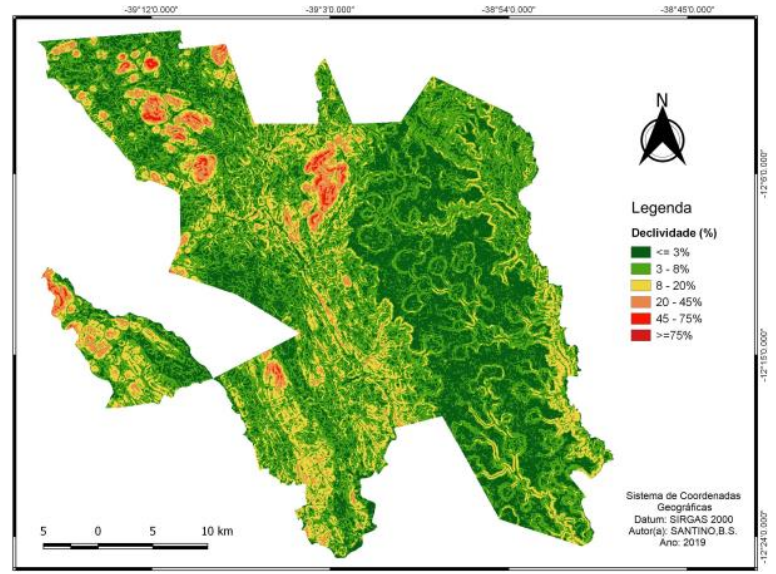

Figura 2. Mapa de declividade do município de Feira de Santana baseado nas classes da embrapa.

Na figura 3 é possível observar no mapa de declividade baseado nos graus de vulnerabilidade a erosão de Crepani et al. (2001), que a maior parte do relevo do município possui declividade acima de $6 \%$, com vulnerabilidade variando de 2 a 3 graus. Os valores mais próximos de 3,0 estão associados a situações de maior declividade, onde prevalecem os processos erosivos da morfogênese (Crepani et al., 2001).

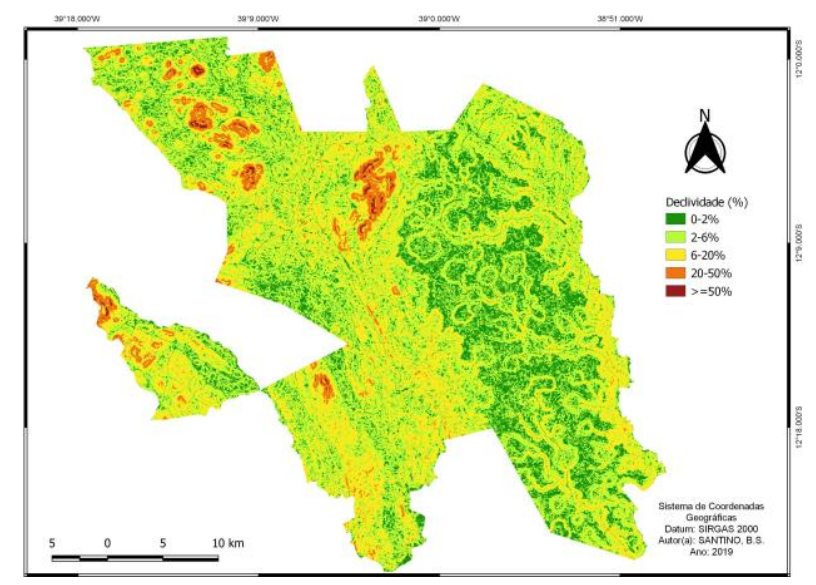

Figura 3. Mapa de declividade do Município de Feira de Santana baseado nos graus de erosão

Na figura 4 foi elaborado o mapa de declividade relacionando as áreas de transição ocorridas de uso do solo da figura $1 \mathrm{com}$ o mapa da figura 3. Nele é possível observar áreas com um grau alto de vulnerabilidade à erosão pelas condições de relevo teve a vegetação nativa substituída para área cultivada. Sabendo que o tipo de cobertura vegetal influencia na capacidade de lixiviação e infiltração do solo (Moura et al, 2018), a implantação de cultivos de ciclo curto, ou pastagem, podem intensificar o processo de erosão por lixiviação, principalmente se as técnicas agrícolas utilizadas forem inadequadas, como por exemplo a não utilização de curvas de nível. 


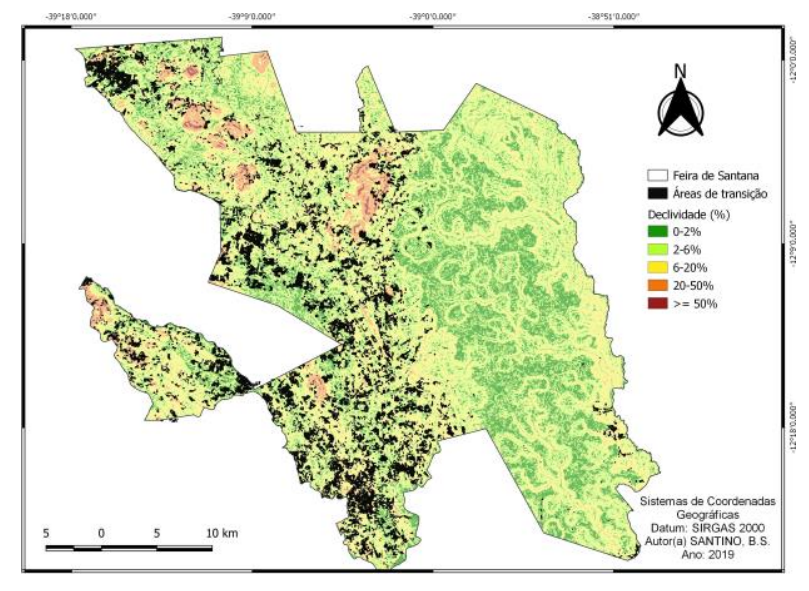

Figura 4. Mapa das áreas de transição da classe Vegetação nativa para Agropecuária, sobrepostas sobre o mapa de declividade baseado nos graus de vulnerabilidade.

\section{CONSIDERAÇÕES FINAIS}

A adoção de medidas de fiscalização das áreas remanescentes é fundamental para preservação do que ainda restou do Bioma Caatinga no município de Feria de Santana. Em relação as áreas onde já houve o desmatamento, o uso de práticas agrícolas agroecológicas como sistemas agroflorestais, quintais ecológicos e plantio em curvas de nível, são peças chave para preservação do solo, evitando consequências mais graves e com difícil reversão como a desertificação, que já é realidade em alguns locais no semiárido.

\section{AGRADECIMENTOS}

Especial agradecimentos ao professor Washington Franca Rocha pelo apoio a partir dos projetos de pesquisas do MAPBIOMAS e INCT Em Estudos Interdisciplinares e Transdisciplinares Em Ecologia E Evolução (IN-TREE).

\section{REFERÊNCIAS}

CREPANI, E.; MEDEIROS, J. D.; HERNANDEZ FILHO, P.; FLORENZANO, T. G.; Duarte, V.; Barbosa, C. C. F. 2001. Sensoriamento remoto e geoprocessamento aplicados ao zoneamento ecológico-econômico e ao ordenamento territorial. São José dos Campos: Inpe.

EMPRESA BRASILEIRA DE PESQUISA AGROPECUÁRIA - EMBRAPA.1979.

Serviço Nacional de Levantamento e Conservação de Solos. In: REUNIÃO TÉCNICA DE LEVANTAMENTO DE SOLOS, 10, 1979, Rio de Janeiro. Súmula...Rio de Janeiro 83p.

CASTELLETTI, C.H.M., J.M.C. SILVA, M. TABARELLI \& A.M.M. SANTOS. 2004. Quanto ainda resta da Caatinga? Uma estimativa preliminar. In: J.M.C. Silva, M. Tabarelli, M.T. Fonseca \& L.V. Lins (orgs.). Biodiversidade da Caatinga: áreas e ações prioritárias para a conservação. pp. 91-100. Ministério do Meio Ambiente, Brasília. ALBUQUERQUE, A. W.; LOMBARDI NETO, F. and SRINIVASAN, V. S.2001. Efeito do desmatamento da caatinga sobre as perdas de solo e água de um Luvissolo em Sumé (PB). Rev. Bras. Ciênc. Solo [online], vol.25, n.1, pp.121-128. ISSN 1806-9657.

CREPANI, E.; MEDEIROS, J. D.; HERNANDEZ FILHO, P.; FLORENZANO, T. G.; Duarte, V.; Barbosa, C. C. F. Sensoriamento remoto e geoprocessamento aplicados ao zoneamento ecológico-econômico e ao ordenamento territorial. São José dos Campos: Inpe, 2001.

EMPRESA BRASILEIRA DE PESQUISA AGROPECUÁRIA - EMBRAPA. Serviço

Nacional de Levantamento e Conservação de Solos. In: REUNIÃO TÉCNICA DE

LEVANTAMENTO DE SOLOS, 10, 1979, Rio de Janeiro. Súmula...Rio de Janeiro, 1979. 83p.

LAGO, A. \& PÁDUA, J.A. (1984) O que é ecologia. São Paulo: Editora Brasiliense 
MOURA, M. M. S. ; ARAÚJO NETO, JOSÉ RIBEIRO DE ; PALÁCIO, H. A. Q. ; BATISTA, F. J. A. ; SOUSA, M. M. M. . Vulnerabilidade à erosão quanto aos aspectos solo e vegetação em uma bacia hidrográfica no semiárido. In: Carlos Senna Soares Farias, Vanessa Barbosa de Alencar, Suedio Alves Meira, David Ribeiro Mourão, Francisco Otávio Landim Neto. (Org.). PLANEJAMENTO URBANO DE BACIAS HIDROGRÁFICAS - ABORDAGENS SOCIOAMBIENTAIS DIVERSAS. 1ed.Mossoró-RN: EDUERN, 2018, v. VII, p. 430-441. para sustentabilidade ambiental. Engenharia Sanitária e Ambiental , v. 19, p. 95-100, 2014. SANTOS, R. A.; MARTINS, D. L. ; SANTOS, R. L.2016 . Balanço Hídrico e Classificação Climática De Thornthwaite em Feira De Santana (Ba). In: Xii Simpósio Brasileiro De Climatologia Geográfica Variabilidade E Suscetibilidade Climática: Implicações Ecossistêmicas E Sociais, Goiânia (GO). ANAIS - XII SBCG, 2016. p. 1889-1900.

SILVA, J. M. C.; TABARELLI, M.; FONSECA, M. T.; LINS, L. V. (org). 2004.

Biodiversidade da Caatinga: áreas e ações prioritárias para a conservação. Brasília (DF): MMA/UFPE/Conservation International - Biodiversitas - Embrapa Semi-árido, 382p.

SOUZA, B. I. F.; ARTIGAS, R. C.; LIMA, E. R. V. 2015. Caatinga e Desertificação. Mercator, Fortaleza (CE), V. 14, N. 1, P. 131-150, Jan./abr.

ZAMBERLAN, JOÃO FERNANDO ; ZAMBERLAN, Carlos Otávio ; SCHUCH JR, VITOR FRANCISCO ; GOMES, CLANDIA MAFFINI ; KNEIPP, JORDANA MARQUES . Produção e manejo agrícola: impactos e desafios . 